\title{
Evolution of MRI Findings in Patients with Idiopathic Intracranial Hypertension after Venous Sinus Stenting
}

\author{
(D) N.F. Belachew, (D). Almiri, (D). Encinas, (D) A. Hakim, (D). Baschung, (D). Kaesmacher, (D). Dobrocky, (D).J. Schankin,
} (D) M. Abegg, (DE.l. Piechowiak, (D)A. Raabe, (D). Gralla, and (DP. Mordasini

\begin{abstract}
BACKGROUND AND PURPOSE: The correlation between imaging findings and clinical status in patients with idiopathic intracranial hypertension is unclear. We aimed to examine the evolution of idiopathic intracranial hypertension-related MR imaging findings in patients treated with venous sinus stent placement.
\end{abstract}

MATERIALS AND METHODS: Thirteen patients with idiopathic intracranial hypertension (median age, 26.9 years) were assessed for changes in the CSF opening pressure, transstenotic pressure gradient, and symptoms after venous sinus stent placement. Optic nerve sheath diameter, posterior globe flattening and/or optic nerve protrusion, empty sella, the Meckel cave, tonsillar ectopia, the ventricles, the occipital emissary vein, and subcutaneous fat were evaluated on MR imaging before and 6 months after venous sinus stent placement. Data are expressed as percentages, medians, or correlation coefficients $(r)$ with $P$ values.

RESULTS: Although all patients showed significant reductions of the CSF opening pressure (31 versus $\left.21 \mathrm{~cm} \mathrm{H}_{2} \mathrm{O} ; P=.005\right)$ and transstenotic pressure gradient $(22.5$ versus $1.5 \mathrm{~mm} \mathrm{Hg} P=.002)$ and substantial improvement of clinical symptoms 6 months after venous sinus stent placement, a concomitant reduction was observed only for posterior globe involvement (61.5\% versus $15.4 \%$; $P=.001$ ), optic nerve sheath diameter $(6.8$ versus $6.1 \mathrm{~mm} ; P<.001)$, and subcutaneous neck fat $(8.9$ versus $7.4 \mathrm{~mm} ; P=.001)$. Strong correlations were observed between decreasing optic nerve sheath diameters and improving nausea/emesis (right optic nerve sheath diameter, $r=0.592, P=.033$; left optic nerve sheath diameter, $r=0.718, P=.006)$, improvement of posterior globe involvement and decreasing papilledema $(r=0.775, P=.003)$, and decreasing occipital emissary vein diameter and decreasing headache frequency $(r=0.74, P=.035)$. Decreasing transstenotic pressure gradient at 6 months strongly correlated with decreasing empty sella $(r=0.625, P=.022)$ and regressing cerebellar ectopia $(r=0.662, P=.019)$.

CONCLUSIONS: Most imaging findings persist long after normalization of intracranial pressure and clinical improvement. However, MR imaging findings related to the optic nerve may reflect treatment success.

ABBREVIATIONS: $I \mathrm{H}=$ idiopathic intracranial hypertension; VAS = visual analog scale

diopathic intracranial hypertension (IIH) is a disorder characterized by increased intracranial pressure that is not caused by a mass lesion, a meningeal process, or cerebral venous thrombosis. ${ }^{1}$ The diagnosis requires a thorough neurologic and ophthalmologic examination, a diagnostic lumbar puncture, and

Received March 22, 2021; accepted after revision July 22.

From the Department of Diagnostic and Interventional Neuroradiology (N.F.B., W.A., R.E., A.H., J.K., T.D., E.I.P., J.G., P.M.), Department of Diagnostic, Interventional and Pediatric Radiology (J.K.), Department of Neurology (C.J.S.), Department of Ophthalmology (M.A.), and Department of Neurosurgery (A.R.), Inselspital, Bern University Hospital and University of Bern, Bern, Switzerland; and Faculty of Medicine (S.B.), University of Bern, Bern, Switzerland.

Please address correspondence to Nebiyat Filate Belachew, MD, Department of Diagnostic and Interventional Neuroradiology, Inselspital, Freiburgstrasse 18, CH3010, Switzerland; e-mail: nebiyatfilate.belachew@insel.ch; @NFBelachew

- Indicates open access to non-subscribers at www.ajnr.org

Indicates article with online supplemental data.

http://dx.doi.org/10.3174/ajnr.A7311 neuroimaging. ${ }^{1}$ Imaging is primarily performed to exclude pathologies that would provide an obvious alternative explanation for clinical and laboratory diagnostic findings. ${ }^{1,2}$ However, several imaging findings, though not specific, may assist in establishing the diagnosis. ${ }^{2,3}$ Neither IIH pathogenesis nor the evolution of imaging findings in patients with $\mathrm{IIH}$ is fully understood. ${ }^{4,5}$ It is particularly unclear whether IIH-associated MR imaging findings provide any information on treatment success. ${ }^{6-10} \mathrm{We}$, therefore, aimed to examine the evolution of IIH-related MR imaging findings in patients treated with venous sinus stent placement.

\section{MATERIALS AND METHODS Inclusion Criteria}

All information was derived from medical record review, MR imaging analyses, and telephone interviews with patients diagnosed with 
IIH who underwent venous sinus stent placement at our hospital between October 2016 and April 2020. Patients were included if they met the following criteria: 1) final diagnosis of IIH according to the modified Dandy criteria; ${ }^{1}$ 2) confirmation of a functionally relevant venous sinus stenosis on DSA and venous sinus manometry; 3) treatment of venous sinus stenosis with venous sinus stent placement; and 4) MR imaging available before and after venous sinus stent placement. Venous sinus stent placement was performed if the condition was deemed refractory to conservative therapy by the treating physicians or treatment had to be stopped due to adverse effects. Venous sinus stenosis with a transstenotic pressure gradient of $\geq 4 \mathrm{~mm} \mathrm{Hg}$ was considered functionally relevant. All 13 patients gave general consent. Ethics approval was obtained from the local ethics committee. All patients included in the current study had previously been examined to assess technical and clinical outcome parameters after venous sinus stent placement (clinical data currently under review).

\section{Analysis of Clinical Information}

Information on age, sex, arterial hypertension, diabetes mellitus, and obesity (including body mass index) was gathered for all patients. Initial IIH-related symptoms such as headache (intensity according to visual analog scale [VAS] of 0-10 and frequency per week), nausea and/or emesis, phono- and photophobia, tinnitus of any kind, diplopia, and other subjective visual disturbances (ie, transient visual obscuration, blurry vision) were documented. Clinical symptoms were listed as IIH-related only if treating physicians had confidently excluded alternative causes. The time from symptom onset to first treatment and the duration of conservative treatment were documented. Additionally, the CSF opening pressure and the presence of papilledema were recorded.

\section{DSA, Venous Sinus Manometry, and Venous Sinus Stent Placement}

Diagnostic DSA and venous sinus manometry were performed with the patient under local anesthesia. The transstenotic pressure gradient was measured as described by Fargen et al. ${ }^{11}$ DSA and venous sinus manometry were repeated with the patient under general anesthesia directly before as well as immediately after venous sinus stent placement to compare the pre- and postinterventional transstenotic pressure gradient. Venous sinus stent placement was performed with the patient under general anesthesia according to institutional protocols and in accordance with the recommendations of Fargen et al. ${ }^{12}$ Patients were preloaded with aspirin, $100 \mathrm{mg} /$ day, and clopidogrel, $75 \mathrm{mg} /$ day, 5 days before the intervention. Aspirin, $100 \mathrm{mg} /$ day, was continued life-long, while clopidogrel was discontinued 6 months after venous sinus stent placement.

\section{Six-Month Follow-up and Outcome}

At the 6-month follow-up, DSA, venous sinus manometry, and diagnostic lumbar puncture for CSF opening pressure measurement were repeated with the patient under local anesthesia. In addition to chart review, patients were interviewed to assess symptoms before venous sinus stent placement as well as changes in all IIH-related symptoms and quality of life after venous sinus stent placement (Online Supplemental Data). The patients' statements were compared with the information in their medical records. The follow-up period (from venous sinus stent placement until the interview) was documented in months for each case. Ophthalmology reports were reviewed to assess the evolution or development of papilledema.

\section{Technical Imaging Information}

MR imaging was performed using a $1.5 \mathrm{~T}$ or a $3 \mathrm{~T}$ MR imaging scanner (1.5T: Magnetom Aera or Magnetom Avanto ${ }^{\text {fit }}$; 3T: Magnetom Skyra ${ }^{\text {fit }}$, Magnetom Prisma, Magnetom Verio, or Magentom Vida; Siemens). Measurements and evaluation of the Meckel cave, the optic nerve sheath diameter, posterior globe flattening, optic nerve protrusion, and empty sella were performed on a 3D isovoxel T2-weighted sampling perfection with application-optimized contrasts by using different flip angle evolution sequence (SPACE; Siemens). Tonsillar ectopia, subcutaneous fat in the scalp and the neck, and the occipital emissary vein were assessed on 3D T1-weighted MPRAGE sequences with contrast media. The acquisition parameters are provided in the Online Supplemental Data. If the relevant sequence was not available for evaluation or was inadequate due to artifacts, the neuroradiologist decided whether reliable assessment was possible on an alternative sequence.

\section{Imaging Analysis}

Posterior globe flattening and optic nerve protrusion were assessed by a senior neuroradiologist (A.H.) with 14 years of experience. All quantitative measurements were performed by 2 independent neuroradiologists (W.A. and R.E.) with 8 and 3.5 years of experience, respectively. All evaluations were performed on the latest scan before venous sinus stent placement and at 6month follow-up. The only exception was patient 4 for whom the only follow-up MR imaging was from 6 days after venous sinus stent placement. Quantitative measurements were repeated 3 times by each neuroradiologist and acquired on different days to avoid recall bias. Posterior globe flattening and optic nerve protrusion were only assessed once on the baseline scan before venous sinus stent placement and the follow-up scan. All imaging data were evaluated in a randomized order. Neuroradiologists were blinded to the clinical conditions of the patients.

The width of the Meckel cave was measured bilaterally on coronal images parallel to the brainstem. The optic nerve sheath diameter was measured bilaterally on axial images perpendicular to the optic nerve. Optic globe involvement was assessed on multiplanar T2-SPACE reconstructions and categorized as normal convexity of the optic globe, posterior globe flattening, or optic nerve protrusion with or without posterior globe flattening. The empty sella was quantified on sagittal images after drawing a line between the tuberculum and dorsum sellae and measuring the maximal perpendicular distance to the superior margin of the pituitary gland. Tonsillar ectopia was quantified on paramedian sagittal images by measuring the shortest distance between the most inferior margins of the cerebellar tonsil and the opisthionbasion line. The maximal thickness of subcutaneous fat was measured on sagittal images perpendicular to the coronal suture (frontal) and posteriorly at the level of the dens axis (occipital). Ventricle size was determined on axial images perpendicular to 

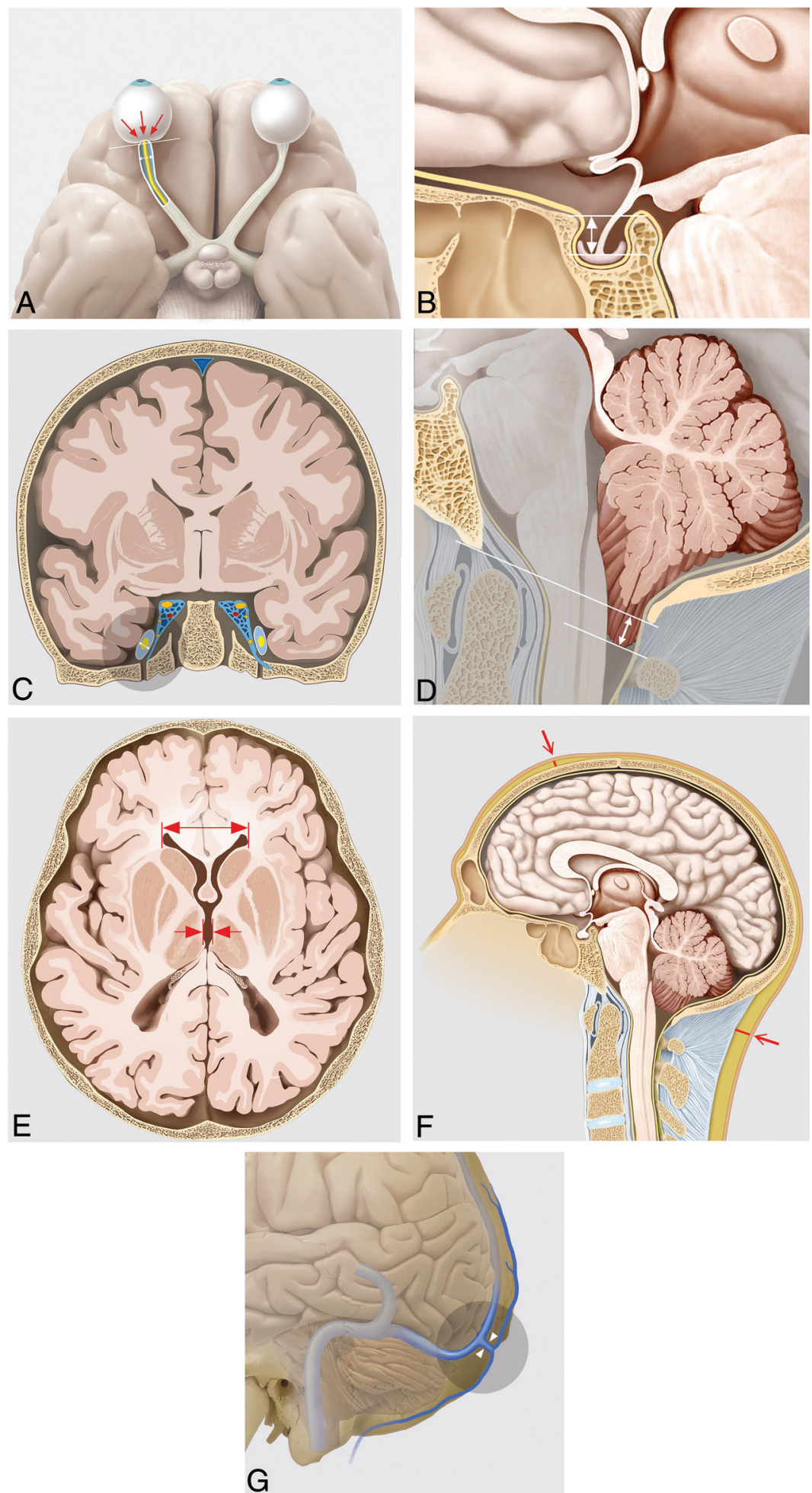

FIG 1. A, Posterior globe flattening (white line), optic nerve protrusion (red arrows), and distension of the optic nerve sheath diameter (white line with arrowheads) in the right eye. B, Measurement technique applied to quantify the empty sella (white line with arrowheads). C, Measurement of the Meckel cave: The circled gray area highlights the width measurement (white line with arrowheads) on the right side. D, Standard measurement to assess cerebellar ectopia (white line with arrowheads). E, Measurement of the distance between the anterior horns of the lateral ventricles (red line with arrowhead) as well as the diameter of the third ventricle corpus (red arrows pointing to perpendicular red lines delimiting the third ventricle corpus). $F$, Measurement of the frontal and occipital subcutaneous fat (red lines). G, Anatomic course of the occipital emissary vein. the brainstem by measuring the distance between the anterior horns of the lateral ventricles and the maximal width of the third ventricle corpus at the same level. As suggested by Hedjoudje et $\mathrm{al}^{13}{ }^{13}$ the occipital emissary vein was measured at its proximal osseous segment whenever it could be identified. Figure 1 illustrates all the MR imaging findings evaluated in this study.

\section{Statistical Analysis}

Data analyses were performed using SPSS Software (Version 25.0; IBM). Continuous parametric variables were compared using the $t$ test for dependent variables, whereas nonparametric variables were compared using the Wilcoxon signed rank test. Mean values were used for statistical analyses of quantitative parameters with repeat measurements by 2 raters. Categoric variables were compared using the Fisher exact test. Results are shown as total values, medians with or without interquartile range (25\%-75\%), or median comparisons with $P$ values for the test applied. Intra- and interobserver agreement was assessed by calculating the intraclass correlation coefficient. Correlation between IIH-related MR imaging findings and clinical improvement was assessed using the Spearman rank correlation coefficient.

\section{RESULTS}

Thirteen patients with IIH who underwent venous sinus stent placement for venous sinus stenosis at our hospital between October 2016 and April 2020 were included in this study. The mean age was 26.9 years (23.3-35.3 years of age). Patients' demographic characteristics and comorbidities are listed in Table 1. All except 1 patient $(n=12 / 13)$ received conservative therapy before venous sinus stent placement, and 1 patient $(n=1 / 13)$ additionally underwent surgical treatment (ventriculoperitoneal shunt). The mean duration of conservative therapy was 18.9 months (6-26 months), and the mean duration of the follow-up period was 16.6 months (7.8-32.2 months). Treatment and symptoms before venous sinus stent placement and at 6-month follow- 
up are summarized in Table 2. Intracranial pressure values before and after venous sinus stent placement are summarized in Table 3.

\section{Pressure Values before and after Venous Sinus Stent Placement}

CSF opening pressure (31 versus $21 \mathrm{~cm} \mathrm{H}_{2} \mathrm{O} ; P=.005$ ) and the transstenotic pressure gradient with the patient under local anesthesia and general anesthesia were significantly lower after venous sinus stent placement compared with before (22.5 versus $1.5 \mathrm{~mm} \mathrm{Hg}, P=.002$; and 9 versus $1 \mathrm{~mm}$ $\mathrm{Hg}, P=.002)$. Reductions of CSF opening pressure $(-9.25$ $\mathrm{cm} \mathrm{H}_{2} \mathrm{O}$ ), transstenotic pressure gradient under local anesthesia $(-8 \mathrm{~mm} \mathrm{Hg})$, and transstenotic pressure gradient under general anesthesia $(-19 \mathrm{~mm} \mathrm{Hg})$ were substantial.

Headache before and after Venous Sinus Stent Placement Six of 11 patients in this study reported experiencing $>1$ type of headache. All patients initially had IIH-related headaches, which

Table 1: Demographics and comorbidities ${ }^{a}$

\begin{tabular}{lcc}
\hline \multicolumn{3}{c}{ Data Available for \% (No.) } \\
\hline Age & $100 \%(13 / 13)$ & $26.9(23.3-35.3)$ \\
Sex (female) (\%) & $100 \%(13 / 13)$ & $100 \%(13)$ \\
Comorbidities & & \\
$\quad$ Diabetes mellitus & $100 \%(13 / 13)$ & $15.4 \%(2)$ \\
Arterial hypertension & $100 \%(13 / 13)$ & $23.1 \%(3)$ \\
Body mass index & $100 \%(13 / 13)$ & $28.9(25.6-36.2)$ \\
Obesity & $100 \%(13 / 13)$ & $15.4 \%(2)$ \\
$\quad$ & & $38.5 \%(5)$ \\
$\quad$ Mone & & $46.2 \%(6)$ \\
$\quad$ Severe & & \\
\hline
\end{tabular}

${ }^{a}$ Data are expressed as percentages (No.) or median (interquartile range [25\%-75\%]). showed complete resolution 6 months after venous sinus stent placement (intensity according to the VAS: 7 versus $0, P=.005$; and frequency per week: 7 versus $0, P=.003$ ).

\section{Other IIH-Related Symptoms before and after Venous Sinus Stent Placement}

Other than headaches, visual disturbances $(n=9 / 13 ; 69.2 \%)$ and tinnitus $(n=8 / 13 ; 61.5 \%)$ were the most common IIH-related symptoms. Papilledema was documented in $9 / 13$ patients. All patients who agreed to be interviewed $(n=11 / 13)$ reported a substantial impairment of their daily life due to IIH-related symptoms before venous sinus stent placement. Mean symptom duration before any treatment was 23.6 months (7.3-52.1 months). The mean duration of conservative therapy was 18.9 months (6.0-26.0 months). All patients who had nausea/emesis $(n=8 / 8)$, photophobia/phonophobia $(n=3 / 3)$, or diplopia $(n=3 / 3)$ showed substantial improvement or complete resolution 6 months after venous sinus stent placement. Almost all patients with tinnitus $(6 / 8$; $75.0 \%)$ or visual disturbances other than diplopia $(8 / 9 ; 88.9 \%)$ showed substantial improvement or complete resolution. For all except 1 patient (who was lost to ophthalmologic follow-up), substantial or complete resolution of papilledema was documented after venous sinus stent placement $(n=8 / 9)$. All patients with available follow-up reported a substantial improvement in the quality of life $(n=11 / 11)$ after venous sinus stent placement.

Table 2: Therapy and symptoms before and after venous sinus stent placement ${ }^{\mathrm{a}}$

\begin{tabular}{|c|c|c|c|c|c|}
\hline \multicolumn{3}{|c|}{ Before Venous Sinus Stent Placement } & \multicolumn{3}{|c|}{ After Venous Sinus Stent Placement } \\
\hline & $\begin{array}{l}\text { Data Available } \\
\text { (\%) (No.) }\end{array}$ & & & $\begin{array}{l}\text { Data Available } \\
\text { (\%) (No.) }\end{array}$ & \\
\hline \multirow[t]{2}{*}{ Headache intensity (VAS) } & $84.6 \%(11 / 13)$ & $7(5.5-9.0)$ & Headache intensity (VAS) & $84.6 \%(11 / 13)$ & $0(0-0)$ \\
\hline & & & $\begin{array}{l}\text { Headache intensity } \\
\text { improvement (VAS) }\end{array}$ & $84.6 \%(11 / 13)$ & $-7(-9$ to -4.5$)$ \\
\hline Headache, frequency (per wk) & $84.6 \%(11 / 13)$ & $7(4.5-7)$ & $\begin{array}{l}\text { Headache frequency (per } \\
\text { wk) }\end{array}$ & $84.6 \%(11 / 13)$ & $0(0-0)$ \\
\hline$\leq 1$ & & $15.4 \%(2)$ & $\leq 1$ & & $84.6 \%(11)$ \\
\hline $2-4$ & & $0.0 \%(0 / 0)$ & $2-4$ & & $0.0 \%(0)$ \\
\hline$>4$ & & $69.2 \%(9)$ & $>4$ & & $0.0 \%(0)$ \\
\hline $\begin{array}{l}\text { Patients with }>1 \text { type of } \\
\text { headache }\end{array}$ & $84.6 \%(11 / 13)$ & $46.2 \%(6)$ & $\begin{array}{l}\text { Headache frequency } \\
\text { improvement (per wk) }\end{array}$ & $84.6 \%(11 / 13)$ & $-7(-7$ to -4.5$)$ \\
\hline Nausea/emesis & $100 \%(13 / 13)$ & $61.5 \%(8)$ & Nausea/emesis IMP-AF & $100 \%(8 / 8)$ & $100 \%(8)$ \\
\hline Photophobia/phonophobia & $100 \%(13 / 13)$ & $23.1 \%(3)$ & $\begin{array}{l}\text { Photophobia/phonophobia } \\
\text { IMP-AF }\end{array}$ & $100 \%(3 / 3)$ & $100 \%(3)$ \\
\hline Tinnitus & $100 \%(13 / 13)$ & $61.5 \%(8)$ & Tinnitus IMP-AF & $100 \%(8 / 8)$ & $75.0 \%(6)$ \\
\hline Diplopia & $100 \%(13 / 13)$ & $23.1 \%(3)$ & Diplopia IMP-AF & $100 \%(3 / 3)$ & $100 \%(3)$ \\
\hline Visual disturbances & $100 \%(13 / 13)$ & $69.2 \%(9)$ & Visual disturbances IMP-AF & $100 \%(9 / 9)$ & $88.9 \%(8)$ \\
\hline Papilledema & $100 \%(13 / 13)$ & $69.2 \%(9)$ & Papilledema IMP-AF & $88.9 \%(8 / 9)$ & $88.9 \%(8)$ \\
\hline Daily life impairment & $84.6 \%(11 / 13)$ & $84.6 \%(11)$ & Daily life quality IMP-AF & $100 \%$ (11/11) & $100 \%(11 / 11)$ \\
\hline Symptom duration (mo) & $100 \%(15 / 15)$ & $23.6(7.3-52.1)$ & Follow-up period (mo) & $100 \%(13 / 13)$ & $16.6(7.8-32.2)$ \\
\hline \multicolumn{6}{|l|}{ Other therapy } \\
\hline Conservative therapy & $100 \%(13 / 13)$ & $92.3 \%(12)$ & & & \\
\hline $\begin{array}{l}\text { Duration of conservative } \\
\text { therapy (in months) }\end{array}$ & $100 \%(15 / 15)$ & $18.9(6-26)$ & & & \\
\hline Surgical therapy & $100 \%(15 / 15)$ & $7.7 \%(1)$ & & & \\
\hline
\end{tabular}

Note:-HA indicates headache; IMP-AF, improvement among affected.

${ }^{a}$ Data are expressed as percentages (No.) or median (interquartile range [25\%-75\%]). 
Table 3: Pressure values before and after venous sinus stent placement ${ }^{a}$

\begin{tabular}{|c|c|c|c|c|c|}
\hline \multicolumn{3}{|c|}{ Before } & \multicolumn{3}{|c|}{ After } \\
\hline & \multirow{2}{*}{\multicolumn{2}{|c|}{$\begin{array}{l}\text { Data } \\
\text { Available } \\
\text { (\%) (No.) }\end{array}$}} & & \multirow{2}{*}{\multicolumn{2}{|c|}{$\begin{array}{l}\text { Data } \\
\text { Available } \\
\text { (\%) (No.) }\end{array}$}} \\
\hline & & & & & \\
\hline \multirow{2}{*}{$\begin{array}{l}\text { CSF opening pressure (cm } \\
\quad \mathrm{H}_{2} \mathrm{O} \text { ) }\end{array}$} & $84.6 \%(11 / 13)$ & $31(23-38)$ & CSF opening pressure $\left(\mathrm{cm} \mathrm{H}_{2} \mathrm{O}\right)$ & $76.9 \%(10 / 13)$ & $21(18.75-29.25)$ \\
\hline & & & $\begin{array}{l}\text { CSF opening pressure } \\
\text { improvement }(\mathrm{mm} \mathrm{Hg})\end{array}$ & $76.9 \%(10 / 13)$ & $-9.25(-20.7$ to -5.7$)$ \\
\hline \multirow[t]{2}{*}{$\begin{array}{l}\text { Transstenotic pressure } \\
\text { gradient in GA }(\mathrm{mm} \mathrm{Hg})\end{array}$} & $100 \%(13 / 13)$ & $9(5-15)$ & $\begin{array}{l}\text { Transstenotic pressure gradient in } \\
\qquad \mathrm{GA}(\mathrm{mm} \mathrm{Hg})\end{array}$ & $100 \%(13 / 13)$ & $1(0-2)$ \\
\hline & & & $\begin{array}{l}\text { Transstenotic pressure gradient } \\
\text { improvement (in } \mathrm{mm} \mathrm{Hg} \text { ) }\end{array}$ & $100 \%(13 / 13)$ & $-8(-15$ to -3.5$)$ \\
\hline \multirow{2}{*}{$\begin{array}{l}\text { Transstenotic pressure } \\
\text { gradient on diagnosis in } \\
\text { LA }(\mathrm{mm} \mathrm{Hg})\end{array}$} & $92.3 \%(12 / 13)$ & $22.5(13.25-26.25)$ & $\begin{array}{c}\text { Transstenotic pressure gradient at } \\
\text { 6-mo follow-up in LA (mm Hg) }\end{array}$ & $92.3 \%(12 / 13)$ & $1.5(0.25-5)$ \\
\hline & & & $\begin{array}{l}\text { Transstenotic pressure gradient } \\
\text { improvement at 6-mo follow- } \\
\text { up (mm Hg) }\end{array}$ & $92.3 \%(12 / 13)$ & $-19(-21.75$ to -13.25$)$ \\
\hline
\end{tabular}

Note:-LA indicates local anesthesia; GA, general anesthesia.

${ }^{a}$ Data are expressed as percentages (No.) or median (interquartile range [25\%-75\%])
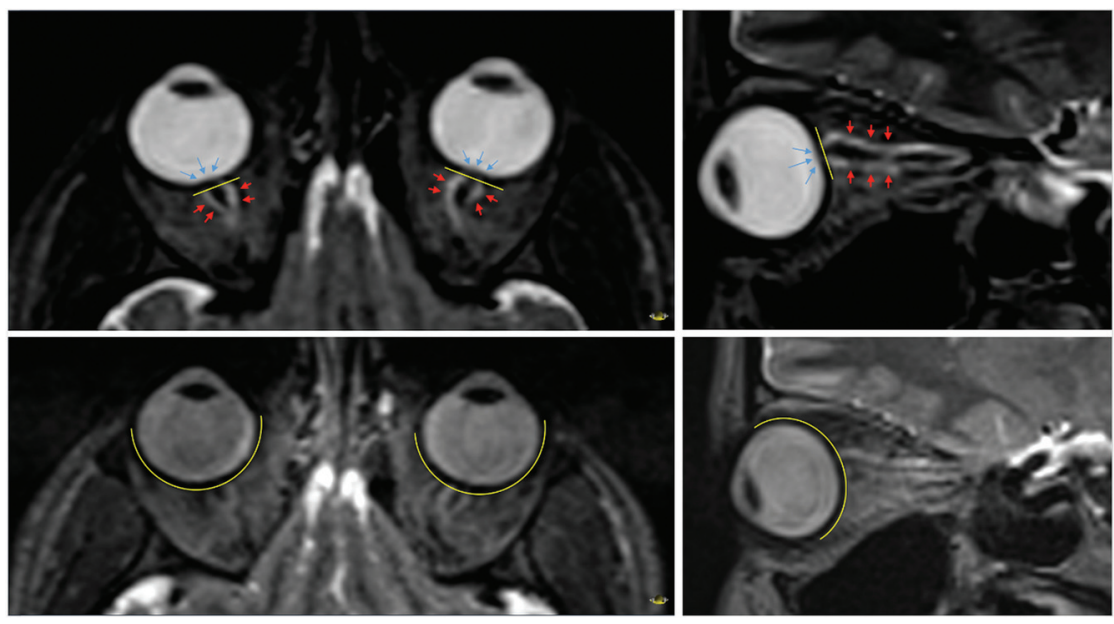

FIG 2. Axial reformation of both eye globes as well as sagittal reformation of the left eye globe along the axis of the optic nerve before (upper images) and after (lower images) stent placement. Before venous sinus stent placement, there is flattening of the posterior sclera (yellow line) with intraocular protrusion of the optic nerve (blue arrows) and distension of the optic nerve sheath diameter due to increased perineural fluid (red arrows). None of these 3 signs are seen after venous sinus stent placement.

\section{IIH-Related MR Imaging Findings before and after a Venous Sinus Stent Placement}

Inter- and intrarater agreement was excellent (intraclass correlation coefficient for raters 1 and 2: 0.968; intraclass correlation coefficient for repeat measurements for rater $1=0.998$ and rater $2=0.968$ ). No differences between measurements at baseline and after venous sinus stent placement were seen for the sella (4.9 versus $4.9 \mathrm{~mm}, P=.753)$, tonsillar ectopia $(-1.1$ versus $-0.67 \mathrm{~mm}, P=.600)$, the lateral ventricles (31.5 versus $32.2 \mathrm{~mm}$, $P=.124)$, the diameter of the proximal occipital emissary vein (1.6 versus $1.6 \mathrm{~mm}, P=.790$ ), or the subcutaneous fat in the scalp (4.1 versus $4.1 \mathrm{~mm}, P=.834$ ). The occipital emissary vein was identified in 11/13 patients (84.6\%) before and after venous sinus stent placement. The width of the Meckel cave tended to decrease, whereas the diameter of the third ventricle corpus had increased on the follow-up scan, though these findings were not statistically significant (4.5 versus $4.2 \mathrm{~mm}, P=.096 ; 3.7$ versus $4.5 \mathrm{~mm}, P=.075)$. Measurements for optic nerve sheath diameter (6.8 versus $6.1 \mathrm{~mm}, P<.001)$ and subcutaneous fat in the neck (8.9 versus $7.4 \mathrm{~mm}$, $P=.001)$ were the only 2 quantitative parameters to have decreased on 6month follow-up imaging. Optic globe involvement improved after venous sinus stent placement (normal convexity of the optic globe: $38.5 \%$ versus $84.6 \%$; posterior globe flattening: $30.8 \%$ versus $15.4 \%$; and posterior globe flattening with optic nerve protrusion: $30.8 \%$ versus $0 \% ; P=.001$ ). Figure 2 exemplifies the improvement in orbital findings after venous sinus stent placement. Changes of quantitative measurements at 6 months did not differ when patients showing improvement of all IIH-related symptoms were compared with patients who had at least 1 persistent symptom. All MR imaging findings evaluated before and after venous sinus stent placement, including the number of MRIs suitable for assessment, are listed in Table 4.

\section{Correlation between Evolution of IIH-Related MR Imaging Findings and Development of Intracranial Pressure Values and IIH-Related Symptoms after Venous Sinus Stent Placement}

Decreasing empty sella height measurements as well as regressing cerebellar ectopia at 6 months correlated strongly with transstenotic pressure gradient improvement with the patient under general 
Table 4: IIH-related MR imaging findings before venous sinus stent placement and at 6-month follow-up ${ }^{a}$

\begin{tabular}{|c|c|c|c|c|}
\hline & & Before Venous Sinus & & \\
\hline MR Imaging Findings & Evaluation Possible (\%) (No.) & Stent Placement & At 6-Month Follow-Up & $P$ Values \\
\hline Meckel cave (mm) & $100 \%(26 / 26)$ & $4.3(4.0-4.9)$ & $4.1(3.4-5.1)$ & .096 \\
\hline Empty sella (mm) & $100 \%(13 / 13)$ & $4.9(3.5-6.9)$ & $4.9(3.2-7.0)$ & .753 \\
\hline Tonsillar ectopia (mm) & $100 \%(13 / 13)$ & $-1.1(-1.9$ to -1.9$)$ & $-0.67(-1.3$ to -0.9$)$ & .600 \\
\hline Lateral ventricles (mm) & $100 \%(13 / 13)$ & $31.5(29.4-34.6)$ & $32.2(29.7-34.6)$ & .124 \\
\hline $\begin{array}{l}\text { Third ventricle corpus } \\
(\mathrm{mm})\end{array}$ & $100 \%(13 / 13)$ & $3.7(3.2-4.2)$ & $4.5(3.5-5.2)$ & .075 \\
\hline $\begin{array}{l}\text { Optic nerve sheath } \\
\text { diameter }(\mathrm{mm})\end{array}$ & $100 \%(26 / 26)$ & $6.8(6.2-7.3)$ & $6.1(5.9-6.5)$ & .000 \\
\hline Optic nerve protrusion (\%) & $100 \%(26 / 26)$ & & & \\
\hline $\begin{array}{l}\text { Posterior globe } \\
\text { involvement (\%) }\end{array}$ & $100 \%(26 / 26)$ & & & .001 \\
\hline $\begin{array}{l}\text { Normal convexity of the } \\
\text { optic globe }\end{array}$ & & $38.5 \%(10)$ & $84.6 \%(22)$ & \\
\hline Posterior globe flattening & & $30.8 \%(8)$ & $15.4 \%(4)$ & \\
\hline $\begin{array}{l}\text { Posterior globe flattening } \\
\text { with optic nerve } \\
\text { protrusion }\end{array}$ & & $30.8 \%(8)$ & $0.0 \%(0)$ & \\
\hline \multicolumn{5}{|l|}{ Extracranial findings } \\
\hline $\begin{array}{l}\text { Proximal emissary vein } \\
(\mathrm{mm})\end{array}$ & $84.6 \%(11 / 13)$ & $1.6(0.6-2.3)$ & $1.6(0.6-2.4)$ & .790 \\
\hline $\begin{array}{l}\text { Subcutaneous fat } \\
\text { thickness in the scalp } \\
(\mathrm{mm})\end{array}$ & $100 \%(13 / 13)$ & $4.1(3.8-4.3)$ & $4.1(3.5-4.6)$ & .834 \\
\hline $\begin{array}{l}\text { Subcutaneous fat } \\
\text { thickness in the neck } \\
(\mathrm{mm})\end{array}$ & $100 \%(13 / 13)$ & $8.9(7.3-11.2)$ & $7.4(5.9-8.3)$ & .001 \\
\hline
\end{tabular}

anesthesia immediately after stent placement (empty sella: $r=0.625, P=.022$; cerebellar ectopia: $r=0.567, P=.043)$ and improvement of the transstenotic pressure gradient with the patient under local anesthesia 6 months after stent placement (empty sella: $r=0.620, P=.032$; cerebellar ectopia: $r=0.662$, $P=.019)$. Decreasing optic nerve sheath diameter on the right side moderately correlated with improvement of transstenotic pressure gradient assessed directly after venous sinus stent placement with the patient under general anesthesia $(r=0.570 ; P=.042)$. Correlations between changes in IIHrelated MR imaging findings and improvement of intracranial pressure values after venous sinus stent placement are summarized in the Online Supplemental Data.

Decreasing optic nerve sheath diameters on both sides correlated with improvement in nausea/emesis (right optic nerve sheath diameter: $r=0.592, P=.033$; left optic nerve sheath diameter: $r=0.718, P=.006)$. Improvement of posterior globe flattening and/or nerve protrusion correlated strongly with improvement of papilledema $(r=0.775$; $P=.003)$. Decreasing empty sella height measurements at 6 months strongly correlated with less improvement of headache intensity assessed with the VAS $(r=-0.661, P=.027)$. Decreasing optic nerve sheath diameter on the left side also correlated strongly with less improvement of headache intensity (VAS) $(r=-0.606, P=.048)$. Decreasing diameter of the proximal occipital emissary vein correlated strongly with decreasing headache frequency $(r=0.741 ; P=.035)$. Online Supplemental Data show an overview of clinicoradiologic correlation results.

\section{DISCUSSION}

The main findings of this study are as follows: 1) Posterior globe flattening and optic nerve protrusion improved at 6-month follow-up, in line with the favorable clinical outcome observed in all patients. 2) In the same period, there was a reduction of optic nerve sheath diameter, and 3) subcutaneous fat in the neck. 4) However, optic nerve sheath diameter remained above the physiologic threshold of $5 \mathrm{~mm} 6$ months after normalization of the CSF opening pressure and the transstenotic pressure gradient. 5) The other MR imaging findings evaluated did not differ at 6 months from those before treatment. 6) Strong correlations were observed between decreasing optic nerve sheath diameter and improving nausea/emesis, improvement of posterior globe involvement, and decreasing papilledema, decreasing empty sella and improving transstenotic pressure gradient, regressing cerebellar ectopia and improving transstenotic pressure gradient, as well as decreasing diameter of the proximal occipital emissary vein and decreasing headache frequency.

Previous studies have shown the high specificity of $\mathrm{IIH}$ associated MR imaging findings, particularly if $>2$ of them can be identified concurrently. ${ }^{3,14}$ However, data regarding the correlation between IIH-associated MR imaging findings and clinical symptoms are scarce. ${ }^{6-10}$ As with CSF analysis, neuroimaging is primarily performed to exclude other diseases affecting the CNS. ${ }^{1,2}$ IIH-related symptoms are diverse and mainly nonspecific. Thus, they are often difficult to quantify. ${ }^{4}$ Consequently, the assessment of treatment success in patients with IIH requires thorough multidisciplinary monitoring and minimally invasive 
procedures such as diagnostic lumbar puncture. Neuroimaging may offer a noninvasive alternative, which could depict treatment success in terms of a decrease of intracranial pressure and the improvement of clinical symptoms.

The results regarding the correlation of orbital MR imaging findings with IIH-related visual symptoms are conflicting. ${ }^{6,8,10,15}$ Our data suggest that they resolve with the normalization of intracranial pressure and the improvement in IIH-related symptoms. However, the optic nerve sheath diameter remained above the threshold of $5 \mathrm{~mm},{ }^{16}$ which indicates that even orbital findings do not simply vanish 6 months after successful treatment. Our findings differing from those in previous studies may be attributed to the lack of standardized protocols for the assessment of IIH-related MR imaging findings. Measurements may also differ depending on the MR imaging sequences used for evaluation. ${ }^{17}$ Automated analysis software packages, which are likely to yield more accurate results than manual measurement techniques, may help solve this problem. ${ }^{15}$ Similar to Wong et al, ${ }^{6}$ our data suggest that the extent of posterior globe involvement on MR imaging reliably reflects the severity of papilledema. Strong correlation between decreasing optic nerve sheath diameter and relief of nausea may indicate that optic nerve involvement plays a role in the pathogenesis of nausea in patients with IIH.

The significant reduction of subcutaneous fat in the neck 6 months after successful treatment is probably associated with lifestyle changes and an increase in daily activity. However, monitoring of weight loss should be a more effective way of assessing treatment success in this regard.

Despite substantial improvement of clinical symptoms and a significant reduction in intracranial pressure, the other imaging findings did not show any relevant changes. Possible explanations include the following: 1) 2D measurement parameters may not reflect the $3 \mathrm{D}$ neuromorphologic changes observed in patients with IIH. 2) IIH-associated MR imaging findings could precede symptom manifestation of $\mathrm{IIH}$, and resolution might be delayed despite clinical improvement. Thus, a 6-month follow-up period may be too short to observe a normalization. 3) Independent factors (ie, genetics) could influence the pace of neuromorphologic recovery. 4) Additional, unrecognized medical conditions may induce neuromorphologic changes similar to IIH (eg, tonsillar ectopia in adult Chiari malformation ${ }^{18}$ ).

The association between IIH-related MR imaging findings in the pituitary gland/stalk and clinical outcome is unclear. ${ }^{6-8,10}$ In this study, the evaluation of the empty sella sign was quantified through repeat measurements intended to increase generalizability and avoid any rater bias. However, many of the above-mentioned problems may also affect our measurements.

None of the patients in our study showed tonsillar ectopia of $>5 \mathrm{~mm}$, though Aiken et $\mathrm{al}^{18}$ found pathologic tonsillar ectopia in $20.9 \%$ patients. Given the low sensitivity of this finding, ${ }^{3}$ future studies will be needed to determine whether patients with $\mathrm{IIH}$ and tonsillar ectopia of $>5 \mathrm{~mm}$ show resolution after successful treatment. Despite strong correlations between improvement of the transstenotic pressure gradient and decreasing empty sella height as well as resolution of cerebellar ectopia, the marginal differences observed at 6 months suggest that neither of these MR imaging findings show sufficient variation to act as imaging biomarkers for intracranial pressure in clinical routine.

Data on whether IIH is associated with an enlargement or narrowing of the Meckel cave are conflicting., ${ }^{9,19}$ Both possibilities may be plausible, depending on the intracranial distribution of CSF pressure. Bialer et $\mathrm{al}^{9}$ found enlargement, defined as "prominent or increased fluid signal expanding the Meckel cave but not distorting the contours," more often in patients with IIH than in controls, but they did not provide a quantifiable threshold. Degnan and Levy ${ }^{19}$ found narrowing of the mediolateral diameter on axial images and suggested a threshold of $4.5 \mathrm{~mm}$. In the present study, median values before and after venous sinus stent placement were below that threshold. However, the width tended to decrease after successful treatment. Assuming that this change occurred in response to the decrease of intracranial pressure, our results suggest that $\mathrm{IIH}$ is associated with enlargement of the Meckel cave. Future studies might examine whether patients with IIH share a common feature that is associated with a narrow Meckel cave, but not directly related to IIH.

Slit-like ventricles were reported in some of the earliest studies examining IIH-associated MR imaging findings. However, their incidence is low, and several studies failed to confirm that slit-like ventricles are observed significantly more often in patients with $\mathrm{IIH}$ than in controls. ${ }^{3}$ Our data suggest that the third ventricle, which tended to be larger at 6-month follow-up, might be more susceptible to changes in intracranial pressure than the lateral ventricles. This possibility could be explained by its central position and overall configuration. The use of automated volume-measuring software might improve the accuracy and reliability of ventricle size assessment. ${ }^{20}$

Hedjoudje et $\mathrm{al}^{13}$ have suggested that occipital emissary veins are more prominent and frequent in patients with IIH. In support of their findings, we were able to identify the proximal occipital emissary vein in nearly all patients with IIH. However, the median diameter was smaller than that found by Hedjoudje et al and had not changed at 6-month follow-up, suggesting poor reflection of treatment success. On the other hand, a strong correlation between the decreasing proximal occipital emissary vein diameter on imaging and decreasing headache frequency may indicate that unlike the other findings, the occipital emissary vein could reflect the frequency of symptom occurrence. The determination of a reliable threshold in terms of pathologic dilation could increase its diagnostic value. However, applicability in clinical routine is restricted because the occipital emissary vein is not an anatomic structure that can always be identified on imaging.

Our results suggest that IIH-associated MR imaging findings unrelated to the optic nerve have limited value in the assessment of treatment success. The lack of relevant change in most MR imaging findings after 6 months despite evident treatment success may not only suggest that they outlast the symptomatic period but could also indicate that they precede it. ${ }^{21}$ Given the increasing rate of obesity and the widespread use of diagnostic neuroimaging worldwide, the number of patients with suspected IIH and the actual incidence of IIH are likely to rise. ${ }^{22}$ Future research may focus on developing imaging scores with high sensitivity and specificity capable of justifying minimally invasive procedures (lumbar puncture or venous sinus manometry) in patients with few or 
nonspecific symptoms. Detection of IIH in the presymptomatic patients or even in the early phase would allow swift treatment, which might influence the course of disease favorably.

\section{Limitations}

Generalizability is limited due to the retrospective, monocentric design of this study. The small number of patients included ( $n=13)$ may have caused sampling error. We exclusively examined patients with IIH treated with venous sinus stent placement; however, the evolution of IIH-related MR imaging findings might differ between patients who received conservative or surgical treatment. Clinical data were incomplete because 2 patients were not available for interview and 1 patient was lost to ophthalmologic follow-up. Only 2 patients showed persistence of at least $1 \mathrm{IIH}-$ related symptom after venous sinus stent placement. Thus, this study provides no data regarding the evolution of IIH-related MR imaging findings in patients who had an unfavorable outcome. There was no healthy control cohort, which could have helped to establish a physiologic variation range for IIH-associated MR imaging findings. There was only a 6-day follow-up MR imaging for patient 4 . This patient was also the only one showing improvement but not complete resolution of posterior globe involvement; this issue may, therefore, have been due to the short follow-up period. Venous sinus stenosis is the most sensitive MR imaging finding associated with $\mathrm{IIH}^{3}$ However, due to device-related artifacts in the ROI, it was not possible to evaluate IIH stenosis reliably on follow-up MR imaging after venous sinus stent placement.

\section{CONCLUSIONS}

Most IIH-related MR imaging findings persist long after normalization of intracranial pressure and clinical improvement. However, MR imaging findings related to the optic nerve may reflect treatment success.

\section{ACKNOWLEDGMENTS}

We thank Susan Kaplan for editorial assistance.

Disclosures: Johannes Kaesmacher-UNRELATED: Grants/Grants Pending: SAMW/ Bangerter Foundation, Clinical Trials Unit, Bern. Christoph J. Schankin-UNRELATED: Consultancy: Novartis, Eli Lilly, Teva Pharmaceuticals, Allergan, Almirall, MindMed; Employment: Zynnon; Expert Testimony: Teva Pharmaceuticals; Grants/Grants Pending: Novartis; Payment for Lectures Including Service on Speakers Bureaus: Novartis, Eli Lilly, Teva Pharmaceuticals, Allergan, Almirall, Amgen, MindMed, Grünenthal; Payment for Development of Educational Presentations: Eli Lilly; Stock/Stock Options: Zynnon; Travel/Accommodations/Meeting Expenses Unrelated to Activities Listed: Teva Pharmaceuticals. Andreas Raabe-UNRELATED: Employment: Inselspital, Neurochirurgische Universitätsklinik. Jan Gralla_UNRELATED: Grants/Grants Pending. Medtronic, Comments: stroke trials: Global Principal Investigator of STAR and SWIFT DIRECT (Medtronic), Consultancy*; Other. Swiss National Foundation, Comments: Swiss National Foundation grant for MRI in stroke.* *Money paid to the institution.

\section{REFERENCES}

1. Friedman DI, Liu GT, Digre KB. Revised diagnostic criteria for the pseudotumor cerebri syndrome in adults and children. Neurology 2013;81:1159-65 CrossRef Medline

2. Holbrook J, Saindane AM. Imaging of intracranial pressure disorders. Neurosurgery 2017;80:341-54 CrossRef Medline

3. Kwee RM, Kwee TC. Systematic review and meta-analysis of MRI signs for diagnosis of idiopathic intracranial hypertension. Eur J Radiol 2019;116:106-15 CrossRef Medline
4. Markey KA, Mollan SP, Jensen RH, et al. Understanding idiopathic intracranial hypertension: mechanisms, management, and future directions. Lancet Neurol 2016;15:78-91 CrossRef Medline

5. Mollan SP, Ali F, Hassan-Smith G, et al. Evolving evidence in adult idiopathic intracranial hypertension: pathophysiology and management. J Neurol Neurosurg Psychiatry 2016;87:982-92 CrossRef Medline

6. Wong H, Sanghera K, Neufeld A, et al. Clinico-radiological correlation of magnetic resonance imaging findings in patients with idiopathic intracranial hypertension. Neuroradiology 2020;62:49-53 CrossRef Medline

7. Zagardo MT, Cail WS, Kelman SE, et al. Reversible empty sella in idiopathic intracranial hypertension: an indicator of successful therapy? AJNR Am J Neuroradiol 1996;17:1953-56 Medline

8. Saindane AM, Bruce BB, Riggeal BD, et al. Association of MRI findings and visual outcome in idiopathic intracranial hypertension. AJR Am J Roentgenol 2013;201:412-18 CrossRef Medline

9. Bialer OY, Rueda MP, Bruce BB, et al. Meningoceles in idiopathic intracranial hypertension. Am J Roentgenol 2014;202:608-13 CrossRef Medline

10. Batur Caglayan HZ, Ucar M, Hasanreisoglu M, et al. Magnetic resonance imaging of idiopathic intracranial hypertension: before and after treatment. J Neuroophthalmol 2019;39:324-29 CrossRef Medline

11. Fargen KM, Spiotta AM, Hyer M, et al. Comparison of venous sinus manometry gradients obtained while awake and under general anesthesia before venous sinus stenting. J Neurointerv Surg 2017;9:990-93 CrossRef Medline

12. Fargen KM, Liu K, Garner RM, et al. Recommendations for the selection and treatment of patients with idiopathic intracranial hypertension for venous sinus stenting. J Neurointerv Surg 2018;10:1203-08 CrossRef Medline

13. Hedjoudje A, Piveteau A, Gonzalez-Campo C, et al. The occipital emissary vein: a possible marker for pseudotumor cerebri. AJNR Am J Neuroradiol 2019;40:973-78 CrossRef

14. Mallery RM, Rehmani OF, Woo JH, et al. Utility of magnetic resonance imaging features for improving the diagnosis of idiopathic intracranial hypertension without papilledema. J Neuroophthalmol 2019;39:299-307 CrossRef Medline

15. Alperin N, Bagci AM, Lam BL, et al. Automated quantitation of the posterior scleral flattening and optic nerve protrusion by MRI in idiopathic intracranial hypertension. AJNR Am J Neuroradiol 2013;34:2354-59 CrossRef Medline

16. Caffery TS, Perret JN, Musso MW, et al. Optic nerve sheath diameter and lumbar puncture opening pressure in nontrauma patients suspected of elevated intracranial pressure. Am J Emerg Med 2014;32:1513-15 CrossRef Medline

17. Golden E, Krivochenitser R, Mathews N, et al. Contrast-enhanced 3D-FLAIR imaging of the optic nerve and optic nerve head: novel neuroimaging findings of idiopathic intracranial hypertension. AJNR Am J Neuroradiol 2019;40:334-39 CrossRef Medline

18. Aiken AH, Hoots JA, Saindane AM, et al. Incidence of cerebellar tonsillar ectopia in idiopathic intracranial hypertension: a mimic of the Chiari I malformation. AJNR Am J Neuroradiol 2012;33:1901-06 CrossRef Medline

19. Degnan AJ, Levy LM. Narrowing of Meckel's cave and cavernous sinus and enlargement of the optic nerve sheath in pseudotumor cerebri. J Comput Assist Tomogr 2011;35:308-12 CrossRef Medline

20. Yepes-Calderon F, Nelson MD, McComb JG. Automatically measuring brain ventricular volume within PACS using artificial intelligence. PLoS One 2018;13:e0193152-14 CrossRef Medline

21. Chan W, Green AL, Mishra A, et al. Transverse venous sinus stenosis in idiopathic intracranial hypertension: a prospective pilot study. Can J Ophthalmol 2020;55:401-05 CrossRef Medline

22. Kilgore KP, Lee MS, Leavitt JA, et al. Re-evaluating the incidence of idiopathic intracranial hypertension in an era of increasing obesity. Ophthalmology 2017;124:697-700 CrossRef Medline 